\title{
Influence of growth parameters on the surface morphology and crystallinity of InSb epilayers grown by liquid phase epitaxy
}

\author{
N K UDAYASHANKAR* and H L BHAT ${ }^{\dagger}$ \\ Department of Physics, National Institute of Technology, Srinivasnagar 575 025, India \\ ${ }^{\dagger}$ Department of Physics, Indian Institute of Science, Bangalore 560 012, India
}

MS received 30 September 2002

\begin{abstract}
Unintentionally doped homoepitaxial InSb films have been grown by liquid phase epitaxy employing ramp cooling and step cooling growth modes. The effect of growth temperature, degree of supercooling and growth duration on the surface morphology and crystallinity were investigated. The major surface features of the grown film like terracing, inclusions, meniscus lines, etc are presented step-by-step and a variety of methods devised to overcome such undesirable features are described in sufficient detail. The optimization of growth parameters have led to the growth of smooth and continuous films. From the detailed morphological, X-ray diffraction, scanning electron microscopic and Raman studies, a correlation between the surface morphology and crystallinity has been established.
\end{abstract}

Keywords. Liquid phase epitaxy; ramp cooling; step-cooling; surface morphology.

\section{Introduction}

In recent years, numerous advances have been made to grow InSb as lattice-matched and strained epilayers for various device applications. New materials like InTISb have also opened up further possibility of their utilization in long wavelength IR region. Although there have been some reports on the preparation of InSb based epilayers by various methods (Caroll and Spivac 1966; Noreika et al 1981, 1983; Bosch et al 1985; Chiang and Bedair 1985; Webb et al 1994), the fabrication of InSb based devices using liquid phase epitaxy has been carried out by relatively a few workers (Melgailis and Calwa 1966; Kumagawa et al 1973). In fact, the growth of InSb is impeded due to the wetting problem of the substrate resulting from the fast oxidation of the InSb surface. This leads to poor surface morphology of the grown layers and in turn poor interface quality of the devices grown on them. Recently, studies carried out on the growth of InSb and InTlSb epilayers using liquid phase epitaxy (LPE) from single phase solution technique showed that this problem could be solved to a large extent by properly selecting the growth temperature and the mode of growth. During the process of optimizing the growth conditions, interesting surface structures and morphologies exhibiting well defined facets were observed depending on the growth conditions. In this paper, detailed studies on nucleation and morphology of InSb epilayers grown at various temperatures from indium-rich solutions combin-

*Author for correspondence ing the two different modes of growth viz. ramp cooling and step cooling modes, are presented. The important growth parameters which were selected for the studies were growth temperature, cooling rate and growth duration. Other experimental parameters like initial heating rates, homogenization time, post-growth cooling program, substrate dimensions, solution height, etc were kept constant in all the runs.

\section{Experimental}

LPE growth was carried out in graphite crucibles placed in a quartz reactor tube which is resistively heated by a single-zone isothermal furnace. The conventional horizontal boat with a slider fabricated from high density graphite was used in the experiments. The graphite boat assembly was cleaned by standard procedures. The reactor tube was also subjected to proper chemical cleaning to get rid off various contaminants. Epitaxial layers were grown on (110) oriented InSb substrates (polished wafer thickness, $450-500 \mu \mathrm{m}$ ) prepared from bulk single crystals grown using horizontal and vertical Bridgman techniques.

As mentioned earlier, two growth routines were used for our experiments: the ramp cooling and step cooling modes. In both the cases, two-phase solution technique was employed wherein the solution containing a floating substrate remained present during the entire period of growth on the seed substrate. In a typical experiment, indium and indium antimonide were taken in solution wells of dimensions $6 \times 6 \times 8 \mathrm{~mm}^{3}$, in weight ratios as prescribed by the solubility curve at the desired saturation temperature. At times the graphite boats with cylindrical 
bins with $8 \mathrm{~mm}$ diameter were also used. The freshly prepared substrates were inserted in the slots made on the slider. Then the solution temperature was increased above the growth temperature and baked for sufficiently long time and allowed to homogenize for an optimum period of $6 \mathrm{~h}$ in ultra-pure hydrogen ambient. In a ramp cooled mode, the growth was initiated by bringing the substrate under the solution and cooling it at the preset rate. The cooling was stopped at the termination temperature and the growth took place during this interval under controlled conditions. Growth was terminated by removing the substrate from under the melt by pulling the slider. In the case of step cooling growth mode, the fast precipitation often led to nonuniform film growth. This was mainly due to the sudden increase in supersaturation level caused by the abrupt decrease in temperature. To overcome this problem, another equilibrium seed was introduced prior to the actual substrate. The introduction of this extra substrate helped to bring down the supersaturation of the solution to the required level. Next, the real substrate was moved in place of the equilibrium seed substrate for the actual controlled growth. In the ramp cooling mode, the cooling rate was varied in steps of $5^{\circ}$ from $5^{\circ} \mathrm{C} / \mathrm{h}$ to $25^{\circ} \mathrm{C} / \mathrm{h}$, whereas the growth duration was varied in steps of $0.5 \mathrm{~h}$ from $0.5 \mathrm{~h}$ to $2 \mathrm{~h}$ for each growth temperature. Similarly, in our step-cooling growth experiments, a supercooling, $(\Delta T)$ in the range of $10-20^{\circ} \mathrm{C}$ below the solution liquidus temperature was employed while the growth duration $\left(t_{\mathrm{G}}\right)$ was varied in steps of $0.25 \mathrm{~h}$ from $0.25-0.75 \mathrm{~h}$ in each case. After the growth, the furnace was moved from the boat region by sliding it on rails, thereby facilitating the cooling of the system at a faster rate. The thickness of the epitaxial layers were measured using a point probe. The surface morphology of the layers was examined using the Leitz-orthoplan microscope in reflection mode. The structural quality of the grown epilayers were also assessed on the basis of Raman spectra, X-ray diffraction peaks and scanning electron microscopy (SEM).

\section{Results and discussion}

\subsection{Ramp cooling}

The surface morphology of LPE grown layers are affected by several factors like substrate preparation, extent of thermal degradation of the substrate prior to growth, inadequate wetting and non-uniform melt back, phase changes due to high impurity levels, degree of melt supersaturation, growth temperature, constitutional supercooling, etc (Mattes and Route 1974; Holmes and Kamath 1980). The selection of proper growth temperature is quite important as the high growth temperature enhances the antimony volatilization from the solution whereas at low temperatures, closer to indium melting point the solution viscosity is high, which influences the melt contact angle with the substrate and affects wetting of the substrate. It was seen from our experiments that, the first visible surface features were observed for growth initiated at $\sim 380^{\circ} \mathrm{C}$. A large number of ripples and usual wavy like patterns were observed (see figure 1a) for a ramp rate $(R)$ of $10^{\circ} \mathrm{C} / \mathrm{h}$. Then keeping the growth temperature constant, the experiments were repeated for various ramp rates and growth duration and no improvement was seen. Next the growth temperature was increased in steps of $10^{\circ} \mathrm{C}$, and growth runs were repeated by changing other two parameters viz. ramp rate and growth duration. It was seen that at $390^{\circ} \mathrm{C}$, with a ramp rate of $10^{\circ} \mathrm{C} / \mathrm{h}$, and for a growth duration of $1 \mathrm{~h}$, the lateral spreading of the ripples was observed on the film surface (figure 1b). Thereafter, several growth runs were made for each selected growth temperature by varying the ramp rate and growth duration in order to reach feature-free smooth epilayers. At $420^{\circ} \mathrm{C}$, continuous film spreading across the field of view was observed. However, the film was slightly warped and exhibited a few pits and inclusions, as can be seen from figure $1 c$.

In an effort to overcome these defects and to get smooth and continuous film the growth temperature $\left(T_{\mathrm{G}}\right)$ and duration were carefully varied in turn. It was observed that for $T_{\mathrm{G}}=425^{\circ} \mathrm{C}, R=25^{\circ} \mathrm{C} / \mathrm{h}$ and a growth duration of 120 min, a smooth and continuous film with large coverage was obtained. During this period a supercooling of $43.7^{\circ} \mathrm{C}$ had occurred and a continuous epilayer of thickness, $25 \mu \mathrm{m}$, had grown although a few indium droplets were left on the surface during the wiping action of the slider (figure 1d). X-ray diffraction spectrum in figure 1e shows apart from a reflection from (220) planes a strong reflection from (101) planes of elemental indium also. It is worth noting that even though an optimum growth temperature plays a vital role on the morphology of the epilayer, cooling rate and hence the level of supersaturation should be fine tuned in order to avoid undesirable surface features on the grown films. In fact, while trying out intermediate cooling rate and supersaturation levels, various surface features were obtained. Figure 2 shows one such terrace structure with a large number of steps bunching out. In this case, the growth was initiated at $400^{\circ} \mathrm{C}$ with a ramp rate of $15^{\circ} \mathrm{C} / \mathrm{h}$ for $30 \mathrm{~min}$. The layer was $\sim 44 \mu \mathrm{m}$ thick. When the ramp rate $(R)$ was gradually increased above $15^{\circ} \mathrm{C} / \mathrm{h}$ by keeping growth temperature and growth duration constant, a few terrace structures along with additional wavy-pattern were observed. A large number of ridges, valleys, inclusions, pits and voids are seen across the surface area (see figure 3 ). This film was grown at $400^{\circ} \mathrm{C}$ with a ramp rate of $20^{\circ} \mathrm{C} / \mathrm{h}\left(t_{\mathrm{G}}=30 \mathrm{~min}\right)$. The depressions and voids could be due to various microparticles or microcrystals in the melt. The InSb microcrystals for instance were frequently nucleated in the supercooled In-InSb solution. This was verified by taking SEM on a substrate surface which showed a large number of crystallites of size of the order of $10 \mu \mathrm{m}$ (figure 4). 
The spurious nucleation of solid throughout the melt has its origin in constitutional supercooling.

It is known that the morphology of the epitaxial layer is governed by conditions at the melt-solid interface during growth. The major factor affecting this interface is the degree of constitutional supercooling, a depression of the liquidus temperature of the melt at the interface created by the depletion of the solute during the growth period. When constitutional supercooling occurs, the growth interface becomes unstable and spurious nuclea-
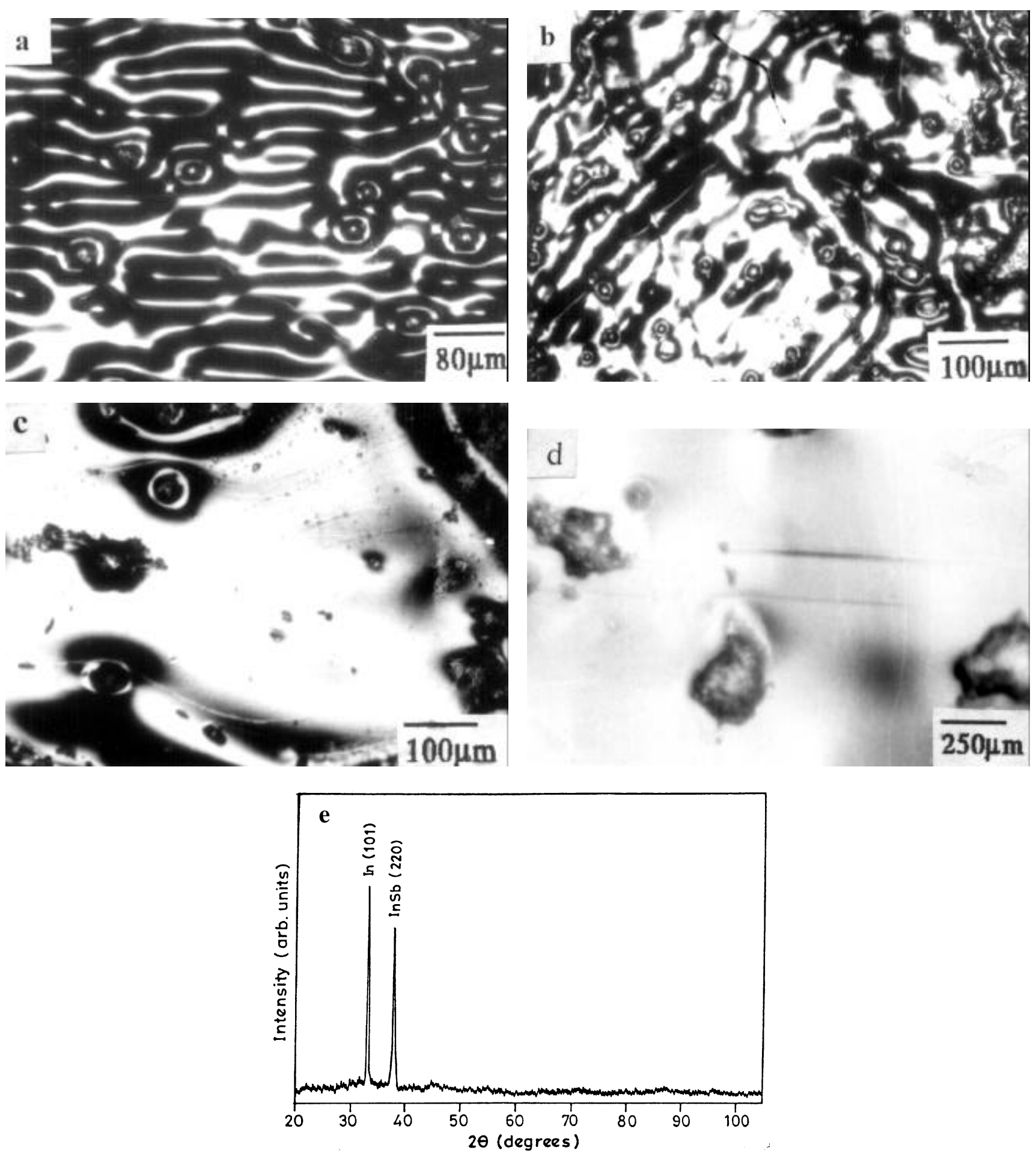

Figure 1. Surface morphologies of as grown InSb epilayers grown by ramp cooling technique under various experimental conditions: a. $T_{\mathrm{G}}=380^{\circ} \mathrm{C}, R=10^{\circ} \mathrm{C} / \mathrm{h}, t_{\mathrm{G}}=45 \mathrm{~min}$, b. $T_{\mathrm{G}}=390^{\circ} \mathrm{C}, R=10^{\circ} \mathrm{C} / \mathrm{h}, t_{\mathrm{G}}=60 \mathrm{~min}, \mathbf{c} . T_{\mathrm{G}}=420^{\circ} \mathrm{C}, R=20^{\circ} \mathrm{C} / \mathrm{h}, t_{\mathrm{G}}=105$ $\min , \mathbf{d} . T_{\mathrm{G}}=425^{\circ} \mathrm{C}, R=25^{\circ} \mathrm{C} / \mathrm{h}, t_{\mathrm{G}}=120 \mathrm{~min}$ and e. XRD spectrum of the film shown in $\mathbf{d}$. 
tion of the solid occurs throughout the melt. When such a solution contacts the substrate, the microcrystals adhere to the substrate and induce the defects, as described above. Such nucleation and growth in front of the substrate surface results in metallic inclusions and cellular growth structures in the epitaxial layer. It is also possible that depressions and voids can be formed due to rough substrate surfaces. Non-uniformity can be caused by strains and imperfections in the bulk material also. Although undesirable from the device point of view, these surface structures help in understanding the mode of growth and enabled to reach optimum experimental conditions to grow good quality epilayers. The disappearance of irregularities at high growth temperatures is attributed to the increase in thermal gradient across the melt-solid interface. This reduces the terrace width by reducing the diffuse interface region, and thereby increasing the nucleation density (Mattes and Route 1974). At the same time, there is also a possibility of terrace formation due to submicroscopic terrace structure left after the usual polishing and etching

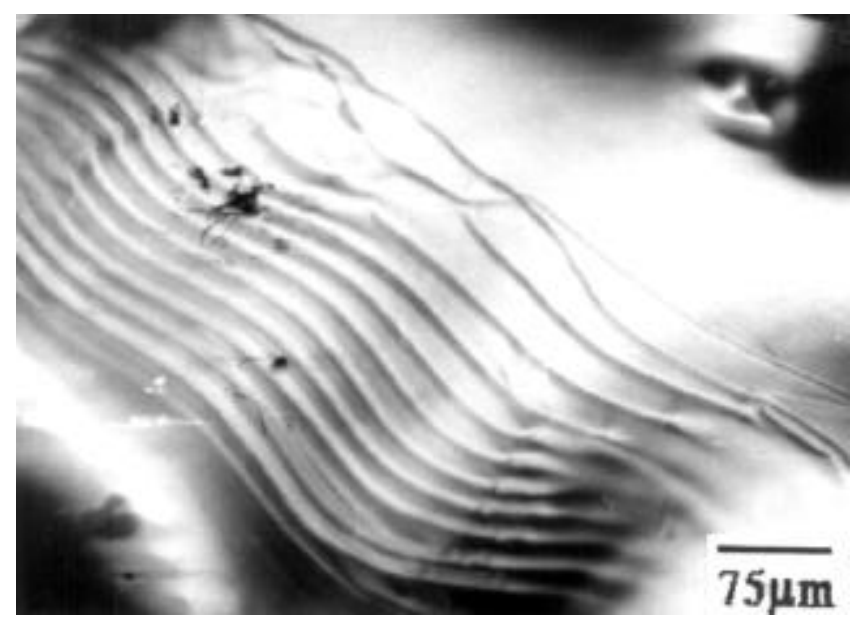

Figure 2. Film showing terrace structures with a large number of steps (thickness, $45 \mu \mathrm{m}$ ).

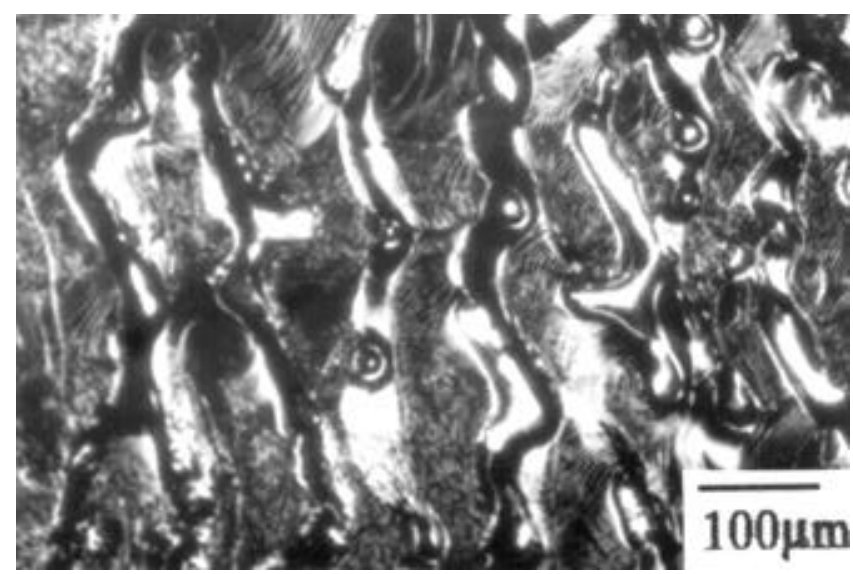

Figure 3. Film showing various surface features like ridges, valleys, inclusions, etc. at the surface of a mislocated substrate as suggested by Bauser et al (1974). The summary of selected growth experiments is also given in the form of table 1.

\subsection{Step cooling}

Typical layer morphologies obtained by the step cooling technique are shown in figure 5. For example, figure 5a shows morphology of a layer grown at $\sim 400^{\circ} \mathrm{C}$, with $\Delta T$ of $10^{\circ} \mathrm{C}$. The surface shows a large number of polygonal islands and are mainly due to the fact that initially, when the growth starts, there is non-uniform nucleation on the substrate caused by the supercooled melt. The increase in growth duration from 15-30 min resulted in considerable change wherein the islands started coalescing and just began to spread out laterally as is clear from figure $5 \mathrm{~b}$. In order to get a smooth layer, the step height was slightly increased and growth duration was varied for each run. It was found that, for $T_{\mathrm{G}}=415^{\circ} \mathrm{C}$ an optimum growth period of $45 \mathrm{~min}$ was sufficient to merge all the polygonal islands to get continuous epilayer with thickness $(t) 25 \mu \mathrm{m}$. Therefore, thereafter, the growth interval was kept constant for subsequent runs and tried to optimize only the growth temperature and step-heights $(\Delta T)$. One such film grown at $415^{\circ} \mathrm{C}$, though continuous, showed very clear step-like features (figure $5 \mathrm{c}$ ). The average thickness of this film was estimated to be $18 \mu \mathrm{m}$. Further, the growth temperature was increased to $425^{\circ} \mathrm{C}$ and several growth runs were made while gradually varying the step-height. The films obtained in these experiments were progressively getting better with decreasing number of undesirable surface features. And, finally, for the same growth temperature, a step height of $20^{\circ} \mathrm{C}$ resulted in the complete transition to smooth and continuous layer $(t=22 \mu \mathrm{m})$ except for a few striations (figure $5 \mathrm{~d}$ ). The summary of

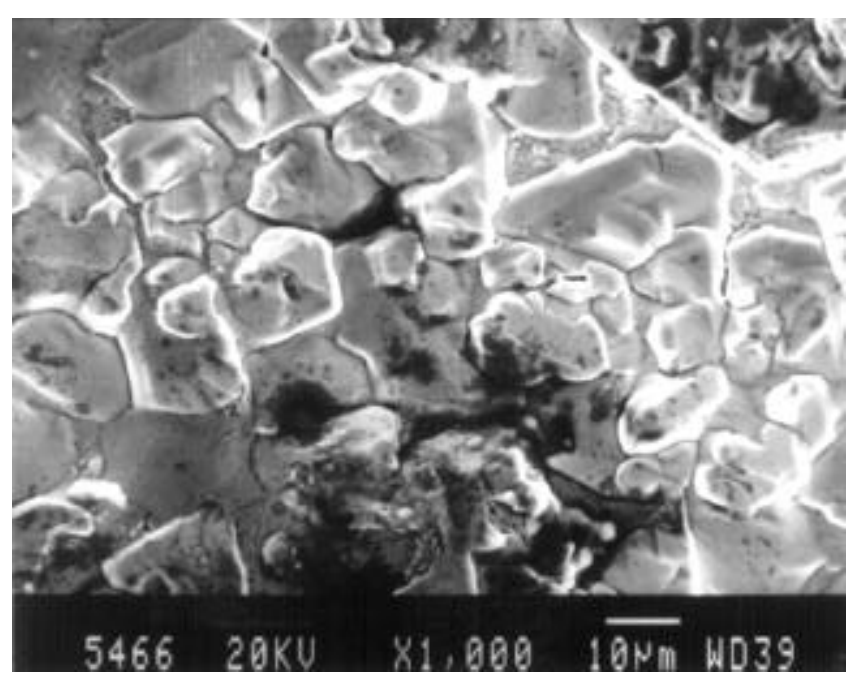

Figure 4. SEM photograph showing a large number of microcrystallites on the substrate-film interface. 
selected growth experiments is also given in the form of table 2 .

It may be noted that the nature of the substrate surface is a critical factor in any epitaxial growth process and can affect the LPE growth in several ways. For example, chemical contamination from pre-growth etching or from inside the LPE unit $\left(\mathrm{O}_{2}, \mathrm{H}_{2} \mathrm{O}\right)$ can lead to patchy or insufficient nucleation. This is particularly a problem in lowtemperature LPE growth of InSb (Mattes and Route 1974), GaSb (Woelk and Benz 1974) and InP (Wrick et al 1976), where native oxides may not be reduced by the ambient hydrogen. Holmes and Kamath (1980) found

Table 1. Summary of selected growth experiments (ramp cooling).

\begin{tabular}{lccccccl}
\hline Growth run & $\begin{array}{c}T_{\mathrm{G}} \\
\left({ }^{\circ} \mathrm{C}\right)\end{array}$ & $\begin{array}{c}R \\
\left({ }^{\circ} \mathrm{C} / \mathrm{h}\right)\end{array}$ & $\begin{array}{c}t_{\mathrm{H}} \\
(\mathrm{h})\end{array}$ & $\begin{array}{c}\Delta T \\
\left({ }^{\circ} \mathrm{C}\right)\end{array}$ & $\begin{array}{c}t \\
(\mu \mathrm{m})\end{array}$ & $\begin{array}{c}R \\
(\mu \mathrm{m} / \mathrm{h})\end{array}$ & \multicolumn{1}{c}{ Remarks } \\
\hline $\mathrm{R} 1$ & 375 & 5 & $0 \cdot 5$ & $2 \cdot 5$ & - & - & - \\
$\mathrm{R} 2$ & 380 & 10 & $0 \cdot 75$ & $7 \cdot 5$ & - & - & wavy pattern, discontinuous \\
R3 & 390 & 10 & 1 & 10 & 10 & 10 & lateral spreading of wavy pattern \\
R4 & 400 & 15 & 1 & 15 & 15 & 15 & merging of islands to form continuous layer \\
R5 & 410 & 15 & $1 \cdot 5$ & 20 & 27 & 18 & appearance of smooth layer \\
R6 & 420 & 20 & $1 \cdot 75$ & 32 & 35 & 20 & continuous film spreading sideways with inclusions scattered \\
R7 & 425 & 25 & 2 & $43 \cdot 7$ & 25 & $12 \cdot 5$ & continuous and smooth film with a few indium droplets \\
\hline
\end{tabular}
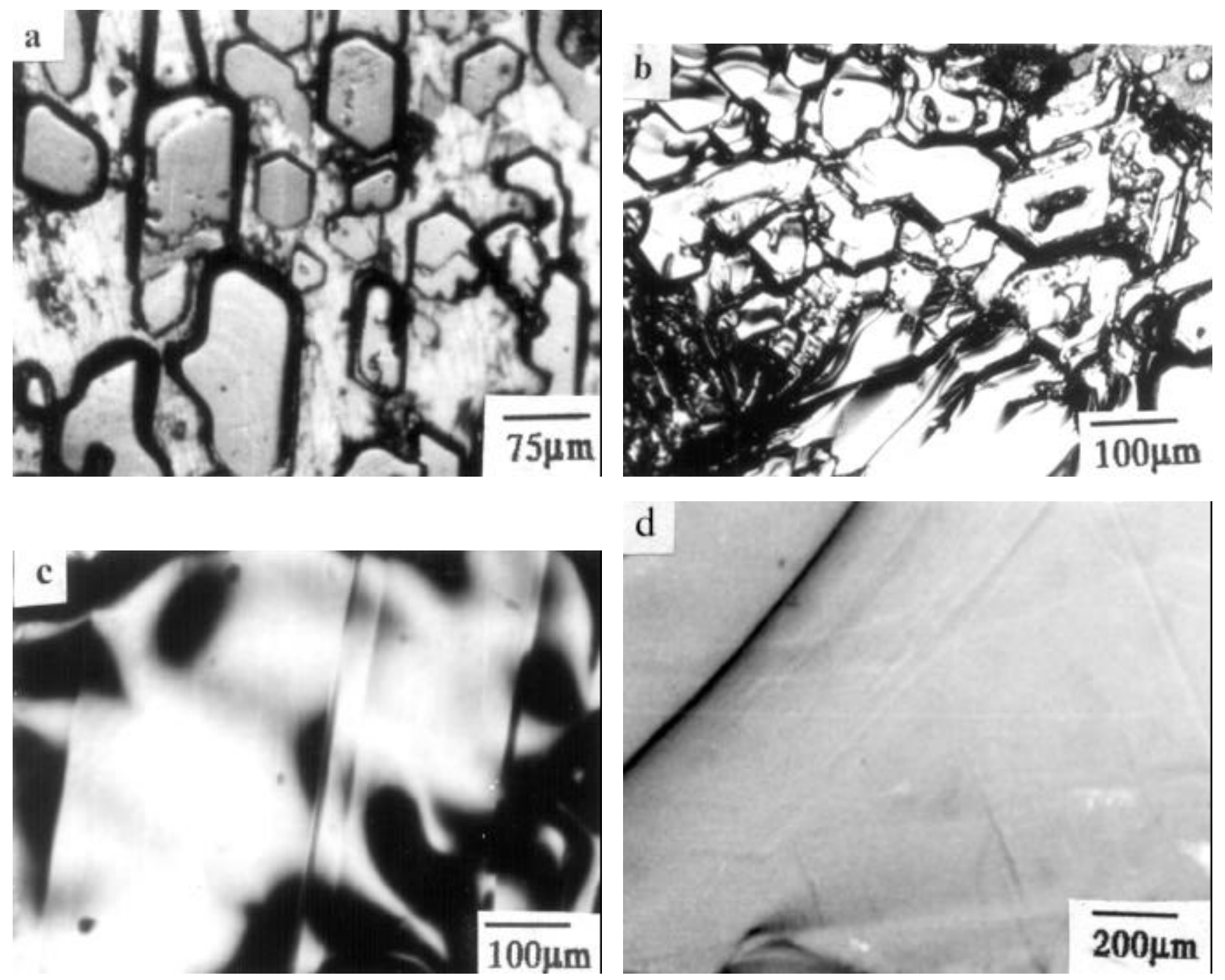

Figure 5. Surface morphologies of as-grown InSb epilayers grown by step-cooling technique under various experimental conditions: a. $T_{\mathrm{G}}=408^{\circ} \mathrm{C}, \Delta T=10^{\circ} \mathrm{C}, t_{\mathrm{G}}=15 \mathrm{~min}$, b. $T_{\mathrm{G}}=410^{\circ} \mathrm{C}, \Delta T=10^{\circ} \mathrm{C}, t_{\mathrm{G}}=30 \mathrm{~min}, \mathbf{c} . T_{\mathrm{G}}=415^{\circ} \mathrm{C}, \Delta T=10^{\circ} \mathrm{C}, t_{\mathrm{G}}=45 \mathrm{~min}$ and d. $T_{\mathrm{G}}=425^{\circ} \mathrm{C}, \Delta T=20^{\circ} \mathrm{C}, t_{\mathrm{G}}=45 \mathrm{~min}$. 
Table 2. Summary of selected growth experiments (step cooling).

\begin{tabular}{lcccccl}
\hline Growth run & $\begin{array}{c}T_{\mathrm{G}} \\
\left({ }^{\circ} \mathrm{C}\right)\end{array}$ & $\begin{array}{c}\Delta T \\
\left({ }^{\circ} \mathrm{C}\right)(\mathrm{Step})\end{array}$ & $\begin{array}{c}t_{\mathrm{H}} \\
(\mathrm{h})\end{array}$ & $\begin{array}{c}T \\
(\mu \mathrm{m})\end{array}$ & $\begin{array}{c}R \\
(\mu \mathrm{m} / \mathrm{h})\end{array}$ & \multicolumn{1}{c}{ Remarks } \\
\hline S1 & 408 & 10 & $0 \cdot 25$ & 20 & 80 & appearance of islands \\
S2 & 410 & 10 & $0 \cdot 5$ & 25 & 50 & merging of islands \\
S3 & 415 & 10 & $0 \cdot 75$ & 18 & 24 & step-like growth features \\
S4 & 420 & 15 & $0 \cdot 75$ & 20 & $26 \cdot 66$ & continuous film with ridges on the sides \\
S5 & 425 & 20 & $0 \cdot 75$ & 22 & $29 \cdot 33$ & continuous and smooth film \\
\hline
\end{tabular}

that for low-temperature LPE growth of InSb and GaInSb on InSb substrates, the proper chemical etching of the substrate was crucial in obtaining uniform nucleation. The surface roughness of the substrate can affect the morphology of an LPE layer grown on it. In fact, this causes marked increase in the nucleation density and hence to smoother surfaces. However, this approach can lead to increased defect densities at the interface and in the growing layer (Ettenberg and Mcfarlane 1974) and hence has not been widely used for growth of device quality layer. The increased nucleation density may be due either to the fact that the rough surface provides a very large surface area of high-index lattice planes on which crystal growth can readily occur by addition of single atoms or to the fact that the roughening process produces a high density of dislocations near the surface which are known to act as nucleation sites.

Further, it was observed that, a deviation of about $\pm 1-2^{\circ} \mathrm{C}$ in the saturation of the melt had only a marginal effect on the final layer thickness. This was quite obvious since the total fall in the temperature was relatively large (in the range $10-30^{\circ} \mathrm{C}$ ). It may be further noted that in the experiments, there was not much correlation between the growth rate $(r)$ and the ramp rate which is consistent with the observations of Kuphal (1991). This is also evident from tables 1 and 2 .

\subsection{Surface morphology and film quality}

In order to obtain the crystalline quality information of the grown films, the X-ray diffraction patterns (XRD) and Raman spectra were taken for a few films. There were quite a few cases wherein grown films showed polycrystallinity due to the possible loss of control over experimental conditions during the growth run as indicated by XRD pattern which exhibited multiple reflections. Figure 6a shows one of these cases wherein film exhibited polycrystallinity with reflections from (111) planes along with those from (220) planes as can be seen from the XRD spectrum given in figure $6 \mathrm{~b}$. In fact, Raman spectrum (figure $6 \mathrm{c}$ ) also showed transverse $\left(\omega_{\mathrm{TO}}\right)$ and longitudinal $\left(\omega_{\mathrm{LO}}\right)$ frequency modes at 180 and $190 \mathrm{~cm}^{-1}$, respectively. The full width at half maximum (FWHM) of the corresponding peaks were determined to be $9.3 \mathrm{~cm}^{-1}$ and $12.5 \mathrm{~cm}^{-1}$, respectively. The broad nature of these peaks shows the polycrystalline nature of the grown films. It is
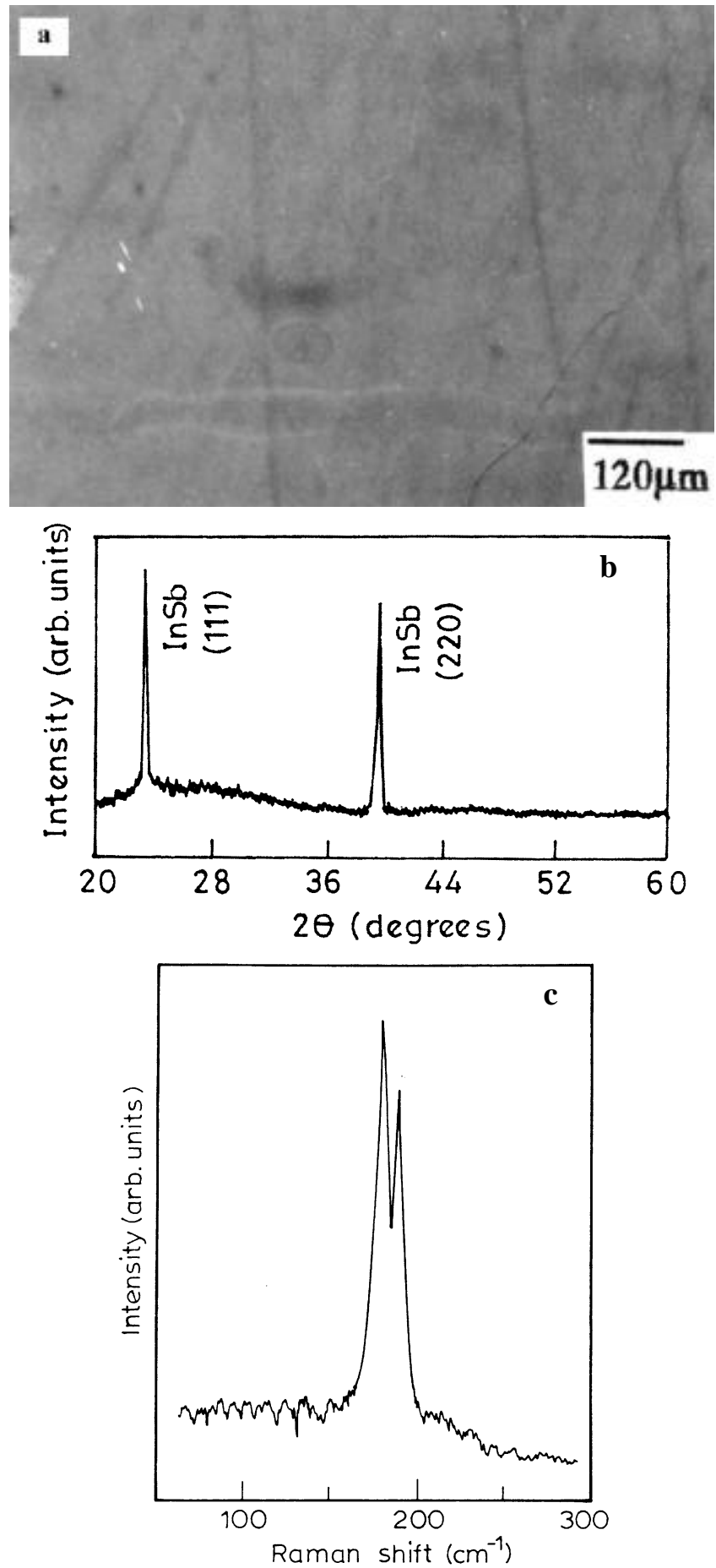

Figure 6. a. Continuous but polycrystalline InSb film, b. XRD pattern and c. Raman spectrum of the film. 
also to be noted that even with best possible control of the growth parameters, prevention of solution carry-over was a daunting task. This problem had to be overcome by employing several accurately machined graphite boats and sliders and taking extreme care in supplying the solution and effecting quick removal of the same after growth. Figure 7a actually shows a step further in the direction of obtaining a good quality film that almost featureless film was grown. However, the film exhibited a set of fine lines across the surface. These are so called meniscus lines which are undesirable from device point of view. This is especially so in the case of multilayered structures as they spoil planarity of the interfaces.

Meniscus lines appear to represent the contour of the trailing edge of the liquid as it moved across the crystal

a
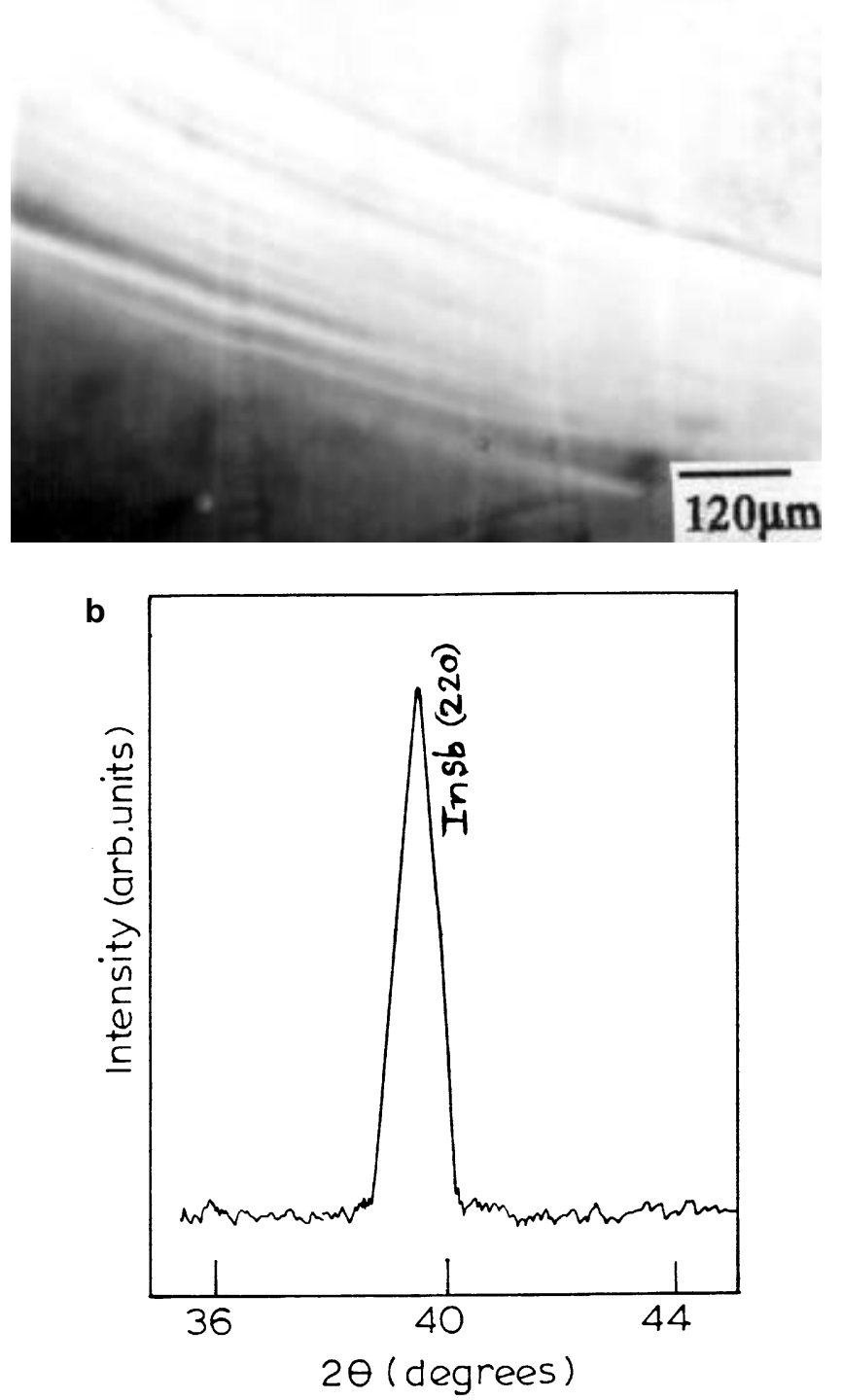

Figure 7. a. Smooth and continuous InSb film (thickness, $25 \mu \mathrm{m}$ ) with a set of meniscus lines on the surface and b. XRD pattern exhibiting single peak (220). during the sliding procedure. Although these are not observable with unaided eye, they may readily be viewed under the microscope. Though several methods (Small et al 1975; Nishitani et al 1976; Bauser 1977) have been proposed to eliminate such defects, the technique of quick supply and removal of the solution was conveniently used in the present growth runs. The crystalline quality of this film can be judged from the XRD pattern shown in figure $7 \mathrm{~b}$ showing a FWHM of $\sim 48$ arc min indicating the need for further improvement. The experiments repeated under optimal conditions showed further improvement in the crystalline quality and morphology over the films as is shown in figure 8. In fact, the best InSb film with excellent epitaxial growth carried out under the maximum possible control of optimal parameters is that shown in figure $8 \mathrm{a}$. It is obvious that the surface is quite smooth,
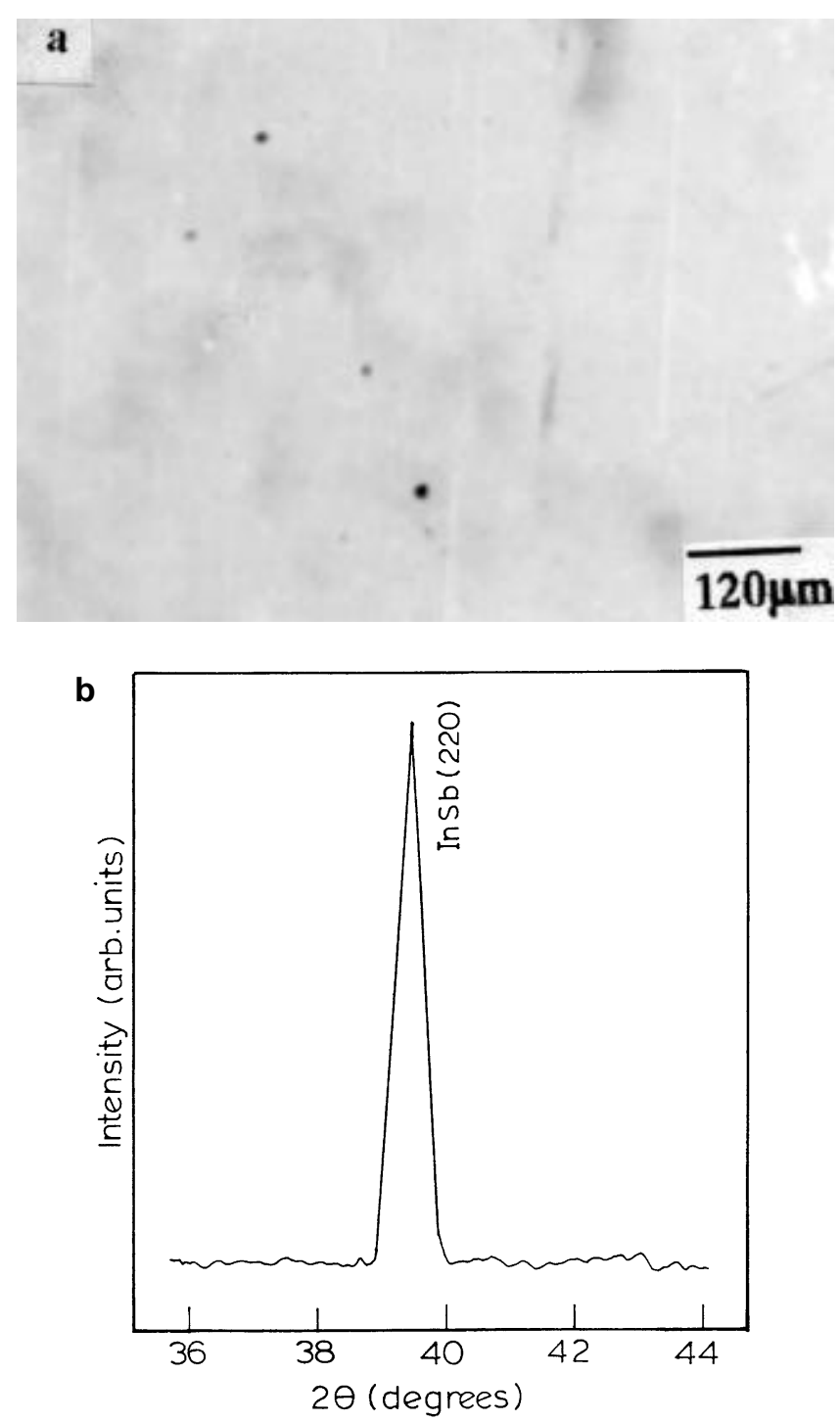

Figure 8. a. Smooth and continuous film (thickness, $22 \mu \mathrm{m}$ ) showing almost featureless surface and b. with narrow (220) peak. 
continuous and free from meniscus lines, etc and is therefore very much 'featureless'. The crystalline quality of the film was also confirmed from an intense reflection from (220) planes (figure 8b). The FWHM for this peak was calculated to be $\sim 25 \mathrm{arc}$ min.

In the absence of FWHM data for InSb homoepitaxial LPE films, one may only compare the present result with the other related semiconductor alloys or the same alloy but grown by different methods. For example, FWHM for AlGaAsSb film grown on GaSb (333) substrate by LPE technique was reported to be 53 arc sec (Bauser 1977). Similarly, the FWHM value for homoepitaxial GaSb prepared by metalorganic magnetron sputtering technique was reported to be $10 \cdot 8$ arc min (Rousina et al 1990). The reported FWHM value for homoepitaxial layer grown by MBE was 18.2 arc sec (McConville et al 1989). From the above comparison it can be inferred that further improvement in the film quality must be possible by resorting to more sophisticated thin film techniques like MOCVD or MBE. Nevertheless, this analysis clearly brings out the close relationship between film morphology and crystalline quality using liquid phase epitaxial technique.

\section{Conclusions}

Undoped InSb epilayers were grown from two-phase solution using liquid phase epitaxy from In-rich solution at various growth temperatures. The effect of selected growth parameters on the morphological evolution of the films was investigated in detail. The surface morphologies of as-grown films were studied and discussed. The typical features like terracing, inclusions, meniscus lines, etc are presented and a variety of methods devised to overcome such undesirable defects were described in sufficient detail. In fact, optimized conditions have led to the growth of smooth and continuous epilayers without any surface features. The optimum growth temperature for the growth of continuous films was found to be $425^{\circ} \mathrm{C}$ for ramp cooling as well as step cooling growth modes. For this optimum growth temperature, it was found that, the degree of supersaturation, $\Delta T=43.7^{\circ} \mathrm{C}$ was required to get continuous films by ramp cooling, whereas the step height of $20^{\circ} \mathrm{C}$ and a growth duration of $45 \mathrm{~min}$ were sufficient to achieve approximately the same thickness in step-cooling growth mode. In addition to the studies on growth mechanisms and their impact on surface morphologies, the crystalline quality of some of the films were also presented and discussed. From these studies, the correlation between film morphology and crystalline quality has been established. The single sharp XRD peak from (220) planes with a FWHM of $\sim 25$ arc min observed for a film grown at $425^{\circ} \mathrm{C}$ substantiates the good quality of the grown homoepitaxial layer of InSb.

\section{Acknowledgement}

One of the authors (NKU) thankfully acknowledges the financial support obtained through DST Project entitled "Crystal growth and characterization of Sb-based compounds for optoelectronic applications".

\section{References}

Bauser E, Frick M, Loechner K S, Schmidt L and Ulrich R 1974 J. Cryst. Growth 27148

Bauser E 1977 Jap. J. Appl. Phys. 16457

Bosch A J, van Welzenis R G and Schannen O F Z J 1985 J. Appl. Phys. 583434

Caroll J A and Spivak J F 1966 Solid State Elec. 9383

Chiang P K and Bedair S M 1985 Appl. Phys. Lett. 48383

Ettenberg M and Mcfarlane S H 1974 J. Cryst. Growth 23 233

Holmes D E and Kamath G S 1980 J. Electron. Matter 995

Kumagawa M, Witt A F, Lichtensteiger M and Gatos H C 1973 J. Electrochem. Soc. 130583

Kuphal E 1991 Appl. Phys. A52 380

Mattes B L and Route R K 1974 J. Cryst. Growth 27133

McConville C F, Whitehouse C R, Williams G M, Cullis A G, Ashley T, Skonick M S, Brown G T and Courtney S J 1989 J. Cryst. Growth 95228

Melgailis I and Calwa A R 1966 J. Electrochem. Soc. 11358

Nishitani Y, Akita K, Nakajima K, Yamaguchi A, Ueda O and Kotani T 1976 J. Cryst. Growth 35279

Noreika A J, Francombe M H and Wood C E C 1981 J. Appl. Phys. Lett. 527416

Noreika A J, Greggi J, Takei W J and Francombe M H 1983 J. Vac. Sci. Technol. A1 558

Rousina R, Halpin C and Webb J B 1990 J. Appl. Phys. 18 2181

Small M B, Blakeslee A E, Shih K K and Potemski R M 1975 J. Cryst. Growth 30257

Webb J B, Lockwood D J and Gnezdilov V P 1994 J. Cryst. Growth $\mathbf{1 3 7} 405$

Woelk C and Benz K W 1974 J. Cryst. Growth 27177

Wrick V, Scilla G J, Eastman L F, Henry R L and Swiggard E M 1976 Electron. Lett. 12394 